\title{
Patient Performed Reading of a Phototest - A Reliable Method?
}

\author{
L. Thorslund ${ }^{1}$ and M. Falk ${ }^{*, 1,2}$ \\ ${ }^{1}$ Department of Medical and Health Sciences, Division of Community Medicine, Primary Care Linköping \\ University, 58185 Linköping, Sweden \\ ${ }^{2}$ The Research and Development Unit for Local Health Care, County of Östergötland, 58185 Linköping, \\ Sweden
}

\begin{abstract}
In various situations, in clinical practice or for prevention purposes directed at skin cancer, a broadened use of phototesting to estimate individual skin UV-sensitivity may be warranted. The aim of the present study was to investigate, in a primary health care population, the reliability of patient performed reading of a UVB phototest, when compared to the reading of a trained physician. Thirty-two subjects, all patients recruited in a primary health care population, underwent a UVB phototest, applied on the forearm. Test reading was performed after 24 hours, by the subjects themselves, by counting the number of erythemal reactions (0-6) detectable, and immediately after this, an independent control reading performed by a doctor was also done. The results showed a $72 \%$ absolute agreement between the subjects' readings and the control readings, and with a weighted kappa-value of 0.78 (95 Cl: $0.64-0.91)$, i.e. corresponding to "substantial agreement". In conclusion, patient performed self-reading of a UVB phototest appears to be a fairly reliable method for estimation of individual skin UV-sensitivity, when compared to the reading of a trained observer. The finding opens up for a broadened use of phototesting in clinical practice and for preventive initiatives aiming at identifying at-risk individuals and reducing sun exposure.
\end{abstract}

Keywords: Phototesting, Ultraviolet radiation, Self-assessment, Test reliability, Skin cancer, Prevention, Risk classification, Skin type, UV-sensitivity, Skin Malignancies.

\section{INTRODUCTION}

Phototesting is routinely used in dermatology, primarily in the clinical assessment and diagnosis of patients with suspected photodermatoses, and for dosimetry purposes in phototherapy. Phototest equipments may vary in design and performance, but the basic principle of phototesting is to provoke the skin with different doses of UV-light, and to grade the skin reaction following provocation. The outcome of provocation is classified in terms of minimal erythema dose (MED), which is defined as the lowest UV-dose capable of causing skin erythema. Testing can be performed for different spectra of UV-light, including both UVA and UVB, narrowband or broadband, and the dose can be regulated either by altering illumination time, or by use of different kinds of photo filters [1,2].

Another field of interest recently investigated in studies, is the possibility of using a phototest in skin cancer prevention $[3,4]$. The connection between people's sun exposure habits in western societies and increasing skin cancer incidence during recent decades, is well documented, and individuals with a sensitive skin type is at extra risk [5-8]. The traditional and most common way of classifying skin reactivity to UV-light is Fitzpatrick's classification, based on selfreported estimation of tendency to burn and tan [9].

*Address corresponding to this author at the Department of Medical and Health Sciences, Division of Community Medicine, Primary Care, Linköping University, 58185 Linköping, Sweden; Tel: +46 1010340 55; Fax: +46 1010340 20; E-mail: magnus.falk@lio.se
The procedure is, however, highly dependent on subjective parameters and has in several studies been demonstrated to correlate poorly with actual UV sensitivity, objectively measured by phototest $[10,11]$. Moreover, people's self-estimated perception of their own individual UV-sensitivity has been found to affect sun exposure habits to higher extent than the actual UV-sensitivity [12]. The idea of using a phototest in the preventive situation has been to increase awareness of individual UV-sensitivity, but also to identify and target prevention towards individuals who are at specific risk from exposing themselves with excessive UV radiation. Also, in the general management of patients with different dermatological conditions, it might be of interest to estimate the patient's reactivity to sun light, as well as to other exposures. Thus, both in the clinical situation, for prevention purposes and in research studies, a broadened ability to perform a phototest would be beneficial.

One of the main obstacles for the performance of a phototest is the fact that it is rather time consuming, since in clinical routine both an initial provocation visit and a second, or even repeated visits, for test reading are needed. Furthermore, test reading is most often performed by specialised personnel, such as a doctor or a trained nurse. A possible way to save time, as well as clinical resources, would be if the patients themselves would be able to read the phototest. In a previous study, this has been tried in a student population, in which reading of a UVB phototest and a 
sodium lauryl sulphate (SLS) patch test was done by the subjects, and compared with readings of a trained observer [13]. In contrast to the "traditional" assessment, the test reading was based on a dichotomous outcome (erythema present or not present), and no detailed scoring of the reactions was required. For the patch test, results showed "substantial agreement" according to kappa-analysis (weighted kappa value 0.76 ), and the phototest "almost perfect agreement" (weighted kappa value 0.83), between the subjects' and the doctor's readings. However, since the study population, consisting of medical students in preclinical stage of education, might not be considered to be representative for a normal population, a similar study performed in patients, would be valuable.

Besides phototesting and patch testing, the selfreading concept has been tried in a few other situations, but the literature is sparse, and results vary. In studies on tuberculin tests, results range from inadequate agreement levels $[14,15]$ to consistently reliable [16-19], in part probably explained by subject material- or instruction-related differences. The dichotomous character of the reading procedure of the tuberculin test, however, is similar to that of the described photest study [13]. In a study on self-reading of skin reactions following chickenpox vaccination, a $90 \%$ agreement was found, and the procedure was stated to be usable for routine vaccination assessment [20]. Other examples where self-reporting by patients have been found to be reliable are reading of a patch test for nickel allergy [21], scoring of hand eczema [22], and self-assessment of vaginal $\mathrm{pH}$ measurement [23, 24]. In some medical fields, a more advanced progress in terms of self-reading has developed, for example self-reporting of blood pressure in patients with hypertension, for which implementation of the procedure has been reported to lead to increased use and reinforced preventive benefits $[25,26]$. This may be viewed as an example of how patient performed self-reading can increase quality of care and at the same time save clinical resources.

The aim of the present study was to investigate, in a primary health care population, the reliability of patient performed reading of a UVB phototest, when compared to the reading of a trained physician.

\section{MATERIALS AND METHODS}

\section{Study Population}

The study was performed at a primary health care centre in south east Sweden. Participants for the study were recruited by a poster located in the waiting room of the health care centre. Age $\geq 18$ years were inclusion criteria, and known history of photodermatosis or present intake of any UV-sensitizising drugs were exclusion criteria. All participants gave informed written consent on their voluntary participation in the study.

\section{Testing Procedure}

The phototest used for the study (Dermalight 80 MED-tester, A.L.T Lichtterapietechnik, Germany) with a broadband fluorescent UV lamp (Philips PL 9W/12) consisted of six $12 \times 12 \mathrm{~mm}$ provocation fields emitting separate increasing doses of UV light, and was applied on the palmar side of the lower arm of the patient. The illumination time was $25 \mathrm{~s}$, which resulted in the following UV doses: 18, 36, 51, 63, 87 and 105 $\mathrm{mJ} / \mathrm{cm}^{2}$. Test provocation was done at the primary health care centre, and after $24 \mathrm{~h}$, the subjects revisited the centre to read the test. This was performed by the subjects themselves, by counting the number of erythematous reactions detectable and then reporting the results on a specific test protocol. They were instructed that each visible reaction, even a barely perceptible erythema, was to be classified as a reaction, a procedure based on the findings of LockAnderson et al. [2] that this criterion for minimal erythema dose (MED) has been shown to be more consistent, in terms of inter-observer variability, than that relating to sharp-bordered reactions. For blinding purpose, the test protocols were placed in closed envelopes, and immediately after the subjects' own test readings, a doctor (one of the authors, M.F.) performed an independent test reading, following the same reading criteria. Furthermore, an additional subscoring of each reaction was also conducted, as follows:

- = negative

$(+)=$ barely perceptible erythema

$1+=$ erythema with a clear border

$2+=$ erythema and oedema

$3+=$ erythema, oedema and papules

4+ = erythema, oedema and vesicles.

\section{Statistical Analysis}

The agreement between patient-performed selfreading and the doctor's control reading, according to the number of positive reactions on each subject, was 
estimated in percent, and by calculation of weighted Kappa. The statistical benefit of Kappa is that it takes into account the possible agreement that could happen by chance, thus being a valuable complement to percentage presentation solely. The smaller sample, the better agreement is needed to gain a high kappa value, since the probability that the observed agreement might be an expression of chance increases. The following guidelines for interpretation of kappa value are usually used: $0-0.20=$ poor agreement, $0.21-0.40=$ fair agreement, $0.41-0.60=$ moderate agreement, $0.61-0.80=$ substantial agreement, 0.80-1.00 = almost perfect agreement [27] . Also, Pearson's $x^{2}$-test was performed to detect possible age and gender related differences in the cases of disagreement between the subjects' and doctor's test readings. In the calculations age was dichotomized to a higher or lower value then the median in the sample.

\section{Ethics Approval}

The study was approved by the Regional Ethics Review Board in Linköping (Dnr M192-09).

Table 1: Outcome of Patient Performed Self-Readings of their Phototests, and the Corresponding Control Readings by Doctor, also Showing the Results of the Detailed Scoring of Each Reaction $(+)=$ Barely Perceptible Erythema, 1+ = Erythema with a Clear Border)

\begin{tabular}{|c|c|c|c|c|c|c|c|c|}
\hline $\begin{array}{l}\text { Number of } \\
\text { subjects }\end{array}$ & $\begin{array}{c}\text { Subject reading } \\
\text { (number of } \\
\text { reactions) }\end{array}$ & $\begin{array}{l}\text { Control reading by } \\
\text { doctor (number of } \\
\text { reactions) }\end{array}$ & \multicolumn{6}{|c|}{ Detailed scoring by doctor, UV-dose $\left(\mathrm{mJ} / \mathrm{cm}^{2}\right)$ : } \\
\hline & 0 & 0 & & & & & & \\
\hline & 0 & 0 & & & & & & \\
\hline & 0 & 0 & & & & & & \\
\hline & 0 & 0 & & & & & & \\
\hline & 1 & 1 & & & & & & $1+$ \\
\hline & 1 & 1 & & & & & & $1+$ \\
\hline & 1 & 1 & & & & & & $1+$ \\
\hline & 1 & 2 & & & & & $(+)$ & $1+$ \\
\hline & 2 & 0 & & & & & & \\
\hline & 2 & 2 & & & & & $1+$ & $1+$ \\
\hline & 2 & 2 & & & & & $(+)$ & $1+$ \\
\hline \multirow[t]{11}{*}{$\mathrm{n}=32$} & 2 & 3 & & & & $(+)$ & $(+)$ & $1+$ \\
\hline & 3 & 2 & & & & & $(+)$ & $1+$ \\
\hline & 3 & 3 & & & & $(+)$ & $1+$ & $1+$ \\
\hline & 3 & 3 & & & & $(+)$ & $1+$ & $1+$ \\
\hline & 3 & 3 & & & & $(+)$ & $1+$ & $1+$ \\
\hline & 3 & 3 & & & & $1+$ & $1+$ & $1+$ \\
\hline & 3 & 3 & & & & $1+$ & $1+$ & $1+$ \\
\hline & 4 & 4 & & & $(+)$ & $1+$ & $1+$ & $1+$ \\
\hline & 4 & 4 & & & $1+$ & $1+$ & $1+$ & $1+$ \\
\hline & 4 & 4 & & & $(+)$ & $1+$ & $1+$ & $1+$ \\
\hline & 5 & 4 & & & $(+)$ & $1+$ & $1+$ & $1+$ \\
\hline
\end{tabular}




\section{RESULTS}

32 voluntary subjects fulfilling inclusion criteria, 11 male and 21 female, between $18-81$ years of age, with a mean age of 49 years, and the median value 47.5 years, joined the study. No subjects needed to be excluded due to the exclusion criteria. Of the 32 subject, 25 subjects reacted to the highest UV dose $\left(105 \mathrm{~mJ} / \mathrm{cm}^{2}\right), 22$ subjects to the second highest $(87$ $\left.\mathrm{mJ} / \mathrm{cm}^{2}\right), 16$ subjects to the third highest $\left(63 \mathrm{~mJ} / \mathrm{cm}^{2}\right)$, and 6 subjects to the fourth highest dose $\left(51 \mathrm{~mJ} / \mathrm{cm}^{2}\right)$, while the remaining 7 subjects did not react to any of the provoked doses. For none of the subjects were the two lowest doses able to cause any reaction.

The results of the subjects' self-readings and doctor's control readings are displayed in Table 1, also showing the outcome of the detailed subscoring performed by the doctor. Absolute agreement between subjects' and doctor's test readings were found in $72 \%$ of cases, and the weighted kappa-value was 0.78 (95 $\mathrm{Cl}: 0.64$ - 0.91), i.e. corresponding to "substantial agreement". Six subjects overestimated, and three subjects underestimated, the number of reactions when compared to the doctor's reading. From the detailed scoring of the reaction, it could be stated that in the cases of underestimation by the subjects, all missed reactions were scored as "barely perceptible erythema".

In Table 2, age and gender distribution according to the level of agreement between subject's and the doctor's control reading is presented. No statistically significant differences in distribution according to these parameters could be detected (Pearson's $X^{2}$-test).

\section{DISCUSSION}

In the light of increasing skin cancer incidence and excessive sun exposure habits in western societies during the past decades, objective methods and strategies to identify at-risk individuals and to communicate sun exposure risks need to be developed and promoted. The environment for this may be in primary health care, at dermatology clinics or in public health situations, but the tools used can likely be similar. In the present study it has been demonstrated that a UVB phototest with a patient performed selfreading procedure, is a fairly reliable method to grade individual skin UV-sensitivity, without the need for excessive clinical resources, which opens up for a broadened use in various situations. The method per se has the advantage of being non-invasive, easy to administer and pedagogical in nature, and - without the need for revisit - also quickly performed.

The traditional Fitzpatrick's classification of skin type has since long been the predominant method of grading skin UV-sensitivity in the broader perspective, i.e. not in the clinical situations where a more accurate estimation, such as in the diagnosis of photodermatoses, is warranted. Several studies, however, have shown the method to be quite unreliable in relation to actual UV-sensitivity $[10,11,28]$, and it has also been demonstrated that its self-estimated outcome may be affected of age and gender, young people (14-18 years of age), and especially young males, more often tend to underestimate their skinsensitivity [10]. Since young people constitute one of the most important target group for preventive measures directed at skin cancer, the performance of a phototest, revealing the actual UV-sensitivity, would thus be preferable compared to self-estimation by means of Fitzpatrick's classification, with high risk of underestimation, in order to communicate individual risk. In a previous study, self-estimated Fitzpatrick's skin type was stronger associated with the level of sun protection than was the actual UV-sensitivity, when measured by phototest [12], which indicates that there

Table 2: Gender and Dichotomized Age Distribution, According to the Level of Agreement Between Subject's and the Doctor's Control Readings, Analyzed with Pearson's $X^{2}$-Test

\begin{tabular}{|c|c|c|c|c|}
\hline & $\begin{array}{c}\text { Patient readings }<\text { control } \\
\text { readings }(n)\end{array}$ & $\begin{array}{c}\text { Patient readings }=\text { control } \\
\text { readings }(n)\end{array}$ & $\begin{array}{c}\text { Patient readings }>\text { control } \\
\text { readings }(n)\end{array}$ & Sign. $\left(X^{2}\right)$ \\
\hline Gender & & & & $p=0.47$ \\
\hline Male & 0 & 8 & 2 & \\
\hline Female & 3 & 15 & 4 & \\
\hline Age & & & & $p=0.18$ \\
\hline$<47.5$ years & 1 & 10 & 5 & \\
\hline$>47.5$ years & 2 & 13 & 1 & \\
\hline
\end{tabular}


might be a need to enlighten at-risk individuals to protect themselves appropriately in regard to how UVsensitive they in fact are.

In the previous study based on self-reading performed by medical students, the results showed a somewhat better agreement with the trained observer reading (85\%) [13], than what was observed in the present study on patients. Additionally, in contrary to the results of the previous study, there was a tendency to overestimate reactions among subjects. There are several possible explanations for this. First, the study populations differed markedly, both with regard to age and educational level, and it is likely to believe that the patient population used in the present study is more representative of a "normal" population, and certainly an ordinary primary health care population, than the student sample. Another circumstance that might have affected the outcome, is the fact that the test reactions in the student-based study was round in shape, instead of square shaped as in the present study, although the significance of this difference appears to be more doubtful. The fact that six subjects overestimated reactions compared to the doctor's reading is interesting, and raises the question whether the development and progress of the erythemal reactions may have played a role. Usually UV-induced erythema is as most pronounced between 10-15 hours after provocation [1, 29, 30], and then declines slowly. It can therefore not be excluded that the subjects may have noticed weak erythemal reactions that had then gone to regress within 24 hours, when the final reading was performed. This could possibly have been avoided technically by covering up the test area after provocation, a procedure that in practice, however, complies poorly with the common test procedure. On the whole, the sparse difference in test reading outcome possibly related to this is likely to be of minor importance in clinical practice.

The location for the application of the phototest may be discussed, since the forearm is perhaps not the most common location used in clinical situations and in studies. Commonly phototests are applied on the upper back or on the buttocks, partly because these areas are quite flat, and partly because they are in general less exposed to sunlight [31-33]. However, application on the inner forearms, as in the present study, is also stated to be appropriate [34], and was a prerequisite for the self-reading procedure. Previous studies indicate that UV-sensitivity tend to be somewhat higher on the back and buttocks than on the arms, but that the difference was slight $[31,35]$. For dosimetry purpose prior to phototherapy, the back and buttocks are likely to be preferable, in order to avoid unwanted excessive sunburn, but e.g. for the use in preventive situations, directed at skin cancer, the difference has reasonably little significance. It is also important to point out that patient performed self-reading is not intended to replace phototest reading by experts, but to be a valuable complement when appropriate.

A weakness of the study is the relatively limited sample size. However, the kappa-analysis takes sample size into account, so that a small sample size demands higher level of percentage agreement to generate a high kappa value. The agreement level found in the present study must thus be considered to be reliable. Another limitation of the study is the fact that control reading was performed by one single doctor. This makes it difficult to relate to the possible effects of inter-observer variability that could have affected the results if there were more than one physician performing the control readings, which has in a previous studies shown to be substantial $[2,36]$. Subsequently, the ultimate setup would be a study with both a somewhat larger subject sample size, and multiple trained observers performing the control readings. There was also a skewness in distribution between gender, females being overrepresented in the study population. This probably reflects that females are in general found to be more interested in health and lifestyle matters [37], and perhaps also that they have been found to look more seriously on sunburn damage than males [38-40].

In conclusion, patient performed self-reading of a UVB phototest appears to be a fairly reliable method for estimation of individual skin UV-sensitivity, when compared to the reading of a trained observer. The finding opens up for a broadened use of phototesting in clinical practice and for preventive initiatives aiming at identifying at-risk individuals and reducing sun exposure.

\section{REFERENCES}

[1] Diffey BL, Farr PM. Quantitative aspects of ultraviolet erythema. Clin Phys Physiol Meas 1991; 12: 311-25. http://dx.doi.org/10.1088/0143-0815/12/4/001

[2] Lock-Andersen J, Wulf HC. Threshold level for measurement of UV sensitivity: reproducibility of phototest. Photodermatol Photoimmunol Photomed 1996; 12: 154-61. http://dx.doi.org/10.1111/j.1600-0781.1996.tb00192.x

[3] Falk M, Anderson C. Prevention of skin cancer in primary healthcare: an evaluation of three different prevention effort levels and the applicability of a phototest. Eur J Gen Pract 2008; 14: 68-75.

http://dx.doi.org/10.1080/13814780802423430 
[4] Falk $\mathrm{M}$, Magnusson $\mathrm{H}$. Sun protection advice mediated by the general practitioner: An effective way to achieve longterm change of behaviour and attitudes related to sun exposure? Scand J Prim Health Care 2011; 29: 135-43. http://dx.doi.org/10.3109/02813432.2011.580088

[5] Boni, R, Schuster C, Nehrhoff B, Burg G. Epidemiology of skin cancer. Neuro Endocrinol Lett 2002; 23(Suppl 2): 48-51.

[6] Diepgen TL, Mahler V. The epidemiology of skin cancer. $\mathrm{Br} \mathrm{J}$ Dermatol 2002; 146(Suppl 61): 1-6. http://dx.doi.org/10.1046/j.1365-2133.146.s61.2.x

[7] Geller AC, Annas GD. Epidemiology of melanoma and nonmelanoma skin cancer. Semin Oncol Nurs 2003; 19: 211. http://dx.doi.org/10.1053/sonu.2003.50000

[8] Leiter U, Garbe C. Epidemiology of melanoma and nonmelanoma skin cancer--the role of sunlight. Adv Exp Med Biol 2008; 624: 89-103.

http://dx.doi.org/10.1007/978-0-387-77574-6 8

[9] Fitzpatrick TB. The validity and practicality of sun-reactive skin types I through VI. Arch Dermatol 1988; 124: 869-71. http://dx.doi.org/10.1001/archderm.1988.01670060015008

[10] Boldeman C, Dal H, Kristjansson S, Lindelöf B. Is selfassessment of skin type a valid method for adolescents? J Am Acad Dermatol 2004; 50: 447-9. http://dx.doi.org/10.1016/j.jaad.2003.08.009

[11] Rampen $\mathrm{FH}$, Fleuren BA, deBoo TM, Lemmens WA. Unreliability of self-reported burning tendency and tanning ability. Arch Dermatol 1988; 124: 885-8. http://dx.doi.org/10.1001/archderm.1988.01670060031011

[12] Falk M. Differences in sun exposure habits between selfreported skin type and ultraviolet sensitivity measured by phototest. Photodermatol Photoimmunol Photomed 2011; 27: 190-5. http://dx.doi.org/10.1111/j.1600-0781.2011.00599.x

[13] Falk M, Anderson C. Reliability of self-assessed reading of skin tests: a possible approach in research and clinical practice? Dermatol Online J 2010; 16: 4.

[14] Howard TP, Solomon DA. Reading the tuberculin skin test. Who, when, and how? Arch Intern Med 1988; 148: 2457-9. http://dx.doi.org/10.1001/archinte.1988.00380110093020

[15] Gourevitch MN, et al. Self-assessment of tuberculin skin test reactions by drug users with or at risk for human immunodeficiency virus infection. Int $\mathrm{J}$ Tuberc Lung Dis 1999; 3: 321-5.

[16] Ozuah PO, Burton W, Lerro KA, Rosenstock J, Mulvihill M. Assessing the validity of tuberculin skin test readings by trained professionals and patients. Chest 1999; 116: 104-6. http://dx.doi.org/10.1378/chest.116.1.104

[17] Selby CD, Allen MB, Leitch AG. How well do the general public read Heaf skin tests? Respir Med 1990; 84: 245-8. http://dx.doi.org/10.1016/S0954-6111(08)80043-1

[18] Prezant DJ, et al. Self-assessment of tuberculin skin test reactions by New York City firefighters: reliability and costeffectiveness in an occupational health care setting. Ann Intern Med 1996; 125: 280-3.

[19] Navin JA, Kaplan JE, Desilvio EL. Self-reading of PPD skin tests. J Am Coll Health 1994. 43: 37-8. http://dx.doi.org/10.1080/07448481.1994.9939083

[20] Huerta, M, Balicer RD, Mimouni D, et al. Validity of selfassessment of skin reaction after smallpox vaccination. Public Health Rep 2006; 121: 45-50.

[21] Josefson A., Svensson, A, Färm G, Engfeldt M, Meding B. Validation of Self-testing as a Method to Estimate the Prevalence of Nickel Allergy. Acta Derm Venereol 2011; 91: 526-30.

[22] Carlsson A, Gånemo A, Anderson CD, Meding B, Stenberg B, Svensson A. Scoring of hand eczema: good agreement between patients and dermatological staff. $\mathrm{Br} \mathrm{J}$ Dermatol 2011; 165: 123-8.

http://dx.doi.org/10.1111/j.1365-2133.2011.10312.x

[23] Kulp JL, Chaudhry S, Wiita B, Bachmann G. The accuracy of women performing vaginal $\mathrm{pH}$ self-testing. $\mathrm{J}$ Womens Health (Larchmt) 2008; 17: 523-6.

http://dx.doi.org/10.1089/jwh.2007.0446

[24] Ferris DG, Francis SL, Dickman ED, Miler-Miles K, Waller JL, McClendon $\mathrm{N}$. Variability of vaginal $\mathrm{pH}$ determination by patients and clinicians. J Am Board Fam Med 2006; 19: 36873.

http://dx.doi.org/10.3122/jabfm.19.4.368

[25] Shaw J, Kerry S, Adjei-Gyamfi Y, et al. Are stroke patients' reports of home blood pressure readings reliable? Crosssectional study. Fam Pract 2011; 28: 118-22. http://dx.doi.org/10.1093/fampra/cmq087

[26] Hamilton W, Round A, Goodchild R, Baker C. Do community based self-reading sphygmomanometers improve detection of hypertension? A feasibility study. J Public Health Med 2003; 25: 125-30. http://dx.doi.org/10.1093/pubmed/fdg027

[27] Brennan P, Silman A. Statistical methods for assessing observer variability in clinical measures. BMJ 1992; 304: 1491-4.

http://dx.doi.org/10.1136/bmj.304.6840.1491

[28] Harrison SL, Buttner PG. Do all fair-skinned Caucasians consider themselves fair? Prev Med 1999; 29: 349-54. http://dx.doi.org/10.1006/pmed.1999.0555

[29] Ilias MA, Falk M, Wårdell K, Anderson C. Phototesting based on a divergent beam--a study on normal subjects. Photodermatol Photoimmunol Photomed 2001; 17: 189-96. http://dx.doi.org/10.1034/j.1600-0781.2001.170409.x

[30] Farr PM, Besag JE, Diffey BL. The time course of UVB and UVC erythema. J Invest Dermatol 1988; 91: 454-7. http://dx.doi.org/10.1111/1523-1747.ep12476577

[31] Leslie KS, Lodge E, Garioch JJ. A comparison of narrowband (TL-01) UVB-induced erythemal response at different body sites. Clin Exp Dermatol 2005; 30: 337-9. http://dx.doi.org/10.1111/j.1365-2230.2005.01845.x

[32] Roelandts R. The diagnosis of photosensitivity. Arch Dermatol 2000; 136: 1152-7. http://dx.doi.org/10.1001/archderm.136.9.1152

[33] Kim JJ, Lim HW. Evaluation of the photosensitive patient. Semin Cutan Med Surg 1999; 18: 253-6. http://dx.doi.org/10.1016/S1085-5629(99)80024-8

[34] Bylaite M, Grigaitiene J, Lapinskaite GS. Photodermatoses: classification, evaluation and management. $\mathrm{Br} \mathrm{J}$ Dermatol 2009; 161 Suppl 3: 61-8. http://dx.doi.org/10.1111/j.1365-2133.2009.09451.x

[35] Gordon PM, Saunders PJ, Diffey BL, Farr PM. Phototesting prior to narrowband (TL-01) ultraviolet B phototherapy. Br J Dermatol 1998; 139: 811-4.

http://dx.doi.org/10.1046/j.1365-2133.1998.02505.x

[36] Falk M, llias M, Anderson C. Inter-observer variability in reading of phototest reactions with sharply or diffusely delineated borders. Skin Res Technol 2008; 14: 397-402. http://dx.doi.org/10.1111/j.1600-0846.2008.00305.x

[37] Svedberg $P$. Attitudes to health promotion interventions among patients in mental health services--differences in relation to socio-demographic, clinical and health-related variables. J Ment Health 2011; 20: 126-35. http://dx.doi.org/10.3109/09638237.2010.507684

[38] Santmyire BR, Feldman SR, Fleischer Jr AB. Lifestyle highrisk behaviors and demographics may predict the level of participation in sun-protection behaviors and skin cancer primary prevention in the United States: results of the 1998 National Health Interview Survey. Cancer 2001; 92: 1315-24. http://dx.doi.org/10.1002/1097-

0142(20010901)92:5<1315::AID-CNCR1453>3.0.CO;2-I 
[39] Branstrom R, Kasparian NA, Chang YM, et al. Predictors of sun protection behaviors and severe sunburn in an international online study. Cancer Epidemiol Biomarkers Prev 2010; 19: 2199-210.

http://dx.doi.org/10.1158/1055-9965.EPI-10-0196
[40] Kasparian NA, McLoone JK, Meiser B. Skin cancer-related prevention and screening behaviors: a review of the literature. J Behav Med 2009; 32: 406-28.

http://dx.doi.org/10.1007/s10865-009-9219-2

Received on 07-04-2012

Accepted on 10-05-2012

Published on 25-06-2012

http://dx.doi.org/10.6000/1927-7229.2012.01.01.12

(C) 2012 Thorslund and Falk; Licensee Lifescience Global.

This is an open access article licensed under the terms of the Creative Commons Attribution Non-Commercial License (http://creativecommons.org/licenses/by-nc/3.0/) which permits unrestricted, non-commercial use, distribution and reproduction in any medium, provided the work is properly cited. 